\title{
Sociodemographic patterns of health insurance coverage in Namibia
}

\author{
Sophie H. Allcock ${ }^{1,2}$, Elizabeth H. Young ${ }^{1,2}$ and Manjinder S. Sandhu ${ }^{1,2^{*}}$
}

\begin{abstract}
Introduction: Health insurance has been found to increase healthcare utilisation and reduce catastrophic health expenditures in a number of countries; however, coverage is often unequally distributed among populations. The sociodemographic patterns of health insurance in Namibia are not fully understood. We aimed to assess the prevalence of health insurance, the relation between health insurance and health service utilisation and to explore the sociodemographic factors associated with health insurance in Namibia. Such findings may help to inform health policy to improve financial access to healthcare in the country.

Methods: Using data on 14,443 individuals, aged 15 to 64 years, from the 2013 Namibia Demographic and Health Survey, the association between health insurance and health service utilisation was investigated using multivariable mixed effects Poisson regression analyses, adjusted for sociodemographic covariates and regional, enumeration area and household clustering. Multivariable mixed effects Poisson regression analyses were also conducted to explore the association between key sociodemographic factors and health insurance, adjusted for covariates and clustering. Effect modification by sex, education level and wealth quintile was also explored.

Results: Just 17.5\% of this population were insured (men: 20.2\%; women: 16.2\%). In fully-adjusted analyses, education was significantly positively associated with health insurance, independent of other sociodemographic factors (higher education RR: 3.98; 95\% Cl: 3.11-5.10; $p<0.001$ ). Female sex (RR: $0.83 ; 95 \%$ Cl: $0.74-0.94 ; p=0.003$ ) and wealth (highest wealth quintile RR: $13.47 ; 95 \%$ Cl: 9.06-20.04; $p<0.001$ ) were also independently associated with insurance. There was a complex interaction between sex, education and wealth in the context of health insurance. With increasing education level, women were more likely to be insured ( $p$ for interaction $<0.001$ ), and education had a greater impact on the likelihood of health insurance in lower wealth quintiles.
\end{abstract}

Conclusions: In this population, health insurance was associated with health service utilisation but insurance coverage was low, and was independently associated with sex, education and wealth. Education may play a key role in health insurance coverage, especially for women and the less wealthy. These findings may help to inform the targeting of strategies to improve financial protection from healthcare-associated costs in Namibia.

Keywords: Health insurance, Namibia, Education, Women, Wealth

\section{Introduction}

Universal Health Coverage (UHC) is defined by the World Health Organization (WHO) to be where "....all people obtain the health services they need without suffering financial hardship when paying for them" [1]. However, the number of people globally facing catastrophic payments on health is rising [2]. Around 800 million people spend

\footnotetext{
* Correspondence: ms23@sanger.ac.uk

${ }^{1}$ Department of Medicine, University of Cambridge, Cambridge, Cambridgeshire, UK

${ }^{2}$ Wellcome Sanger Institute, Wellcome Genome Campus, Hinxton, Cambridgeshire CB10 1SA, UK
}

more than $10 \%$ of household expenditure on health and around 100 million people are being pushed into extreme poverty every year due to out-of-pocket (OOP) expenditures on health [2].

Namibia is committed to achieving UHC. As an upper-middle income country, with a small population of around 2.5 million people, Namibia's total health expenditure (THE) as a percentage of gross domestic product (GDP) and per capita health expenditure are comparatively high relative to other sub-Saharan African countries [3-5]. Healthcare in Namibia is funded through

(c) The Author(s). 2019 Open Access This article is distributed under the terms of the Creative Commons Attribution 4.0 International License (http://creativecommons.org/licenses/by/4.0/), which permits unrestricted use, distribution, and reproduction in any medium, provided you give appropriate credit to the original author(s) and the source, provide a link to the Creative Commons license, and indicate if changes were made. The Creative Commons Public Domain Dedication waiver (http://creativecommons.org/publicdomain/zero/1.0/) applies to the data made available in this article, unless otherwise stated. 
Government funding, prepaid private expenditure, OOP expenditure and donor funding [4]. In 2014/15, 64\% of THE was provided by the Namibian Government, which equated to around 13\% of government expenditure for the fiscal year [4]. Additionally, household expenditures on health fall well below the level indicative of catastrophic health expenditures [6]. However, despite its strong financial position, Namibia may still face challenges to achieving UHC. Namibia experiences substantial wealth inequality across the population [7], which may affect the ability of individuals and households to afford healthcare [8]. Additionally, THE is unevenly distributed, with $36 \%$ of THE providing health insurance that covers less than one fifth of the population [4]. Given these inequities in health financing in Namibia, additional financial resources may be needed to realise UHC [4].

Health insurance and other pre-financing mechanisms have been identified as important components of UHC strategies [9-12]. Health insurance has been associated with health-seeking behaviour across sub-Saharan Africa (SSA) and has been found to reduce OOP expenditures, catastrophic spending on health, financial barriers to healthcare, and to protect against poverty in a number of developing countries [13-22]. In Namibia, health insurance has been associated with cancer screening [2325 ], timely antenatal care visits and skilled attendance at birth [26, 27], as well as reductions in the economic consequences of HIV-associated health costs [28]. However, the impact of health insurance on health-seeking behaviour more broadly is less well understood in the country. In addition to understanding the coverage of health insurance in a population, it is also important to assess equity in health insurance coverage. Inequalities in Namibia, such as the country's high income inequality, notable unemployment rate and variable access to and completion of education [7, 29-31], may directly or indirectly impact upon the ability of households to afford healthcare or health insurance. Wealth and education have been widely associated with having insurance in other settings [32-38]; by comparison, the sociodemographic factors associated with health insurance in Namibia have not been well described.

As health insurance is one strategy that could help to achieve UHC, it will be important to assess equity in health insurance coverage across different sociodemographic groups. A better understanding of the sociodemographic factors that are associated with health insurance coverage may help to inform the design and implementation of strategies to improve financial protection from healthcare-associated costs. As such, we first aimed to investigate the relation between health insurance and health service utilisation, and secondly to explore the coverage of health insurance and the demographic factors associated with health insurance in Namibia, using data from the 2013 Namibia Demographic and Health Survey (DHS).

\section{Methods \\ Data sources}

To understand the distribution and determinants of health insurance and health service utilisation on a national scale, we used data from the 2013 Namibia DHS. The methods of the 2013 Namibia DHS are described in detail elsewhere [39]. In summary, the DHS included three surveys: the Household Questionnaire, Woman's Questionnaire and Man's Questionnaire. Through these surveys, data were collected on 9849 households and 41,646 household members, including in-depth individual data on 10,018 women and 4481 men [39]. The sampling strategy was a two-stage stratified sample design, where stage one involved the selection of enumeration areas (EAs) using stratified proportional size selection [39]. Stage two constituted the random selection of around 20 households within each of the selected EAs [39]. Survey responses were high at over $90 \%$ for the Household and Woman's Questionnaires and 85\% for the Man's Questionnaire [39].

The DHS data are useful for understanding the determinants of health insurance due to the extensive data collected on sociodemographic factors as well as health insurance coverage and health-seeking behaviour (including inpatient and outpatient care). Questions related to health insurance were asked as part of the Woman's and Man's Questionnaires. Individuals were asked if they were covered by health insurance and, if so, what type of health insurance they were covered by [39]. Questions related to inpatient and outpatient care seeking were asked to the respondent who answered the Household Questionnaire and included information about the reason for seeking healthcare, the number of visits and the cost of the care.

Education level reflects the highest level of education attended [40], but does not necessarily mean that the level of education was completed. The wealth quintile variable is based on a wealth index factor score, generated using principal components analysis, which was derived from data collected pertaining to household assets, household construction materials and sanitation facilities [40, 41]. Therefore, wealth quintile is a household-level factor, not an individual factor.

\section{Statistical analyses}

All analyses were carried out using Stata 14 software package (StataCorp: College Station, TX, USA). The Household, Woman's and Man's datasets were merged and data were cleaned. A subset of 14,443 individuals (9985 women and 4458 men) with information on age, sex, education level, occupation, wealth, residence type, region, marital status and health insurance were 
included in these analyses. Individuals with occupations classed as "other" were also excluded.

Age was recoded into five-year groups, with those aged 50 to 64 years included in one category. Occupation was recoded into four categories: Professional (including clerical, sales, services), agricultural (including self-employed and employee), manual (including skilled and unskilled) and unemployed. Marital status was recoded to include individuals who were divorced, widowed or no longer living with their partner in the formerly/ever married category. To explore outpatient health seeking behaviour, a variable for whether individuals did or did not seek outpatient care in the four weeks preceding the survey was generated. This was done based on the line number of the individual who sought care. Individuals whose line number matched that of the variable for the line number of the person seeking outpatient care were coded as "1" and those whose line numbers did not match were coded as "0" (not having sought outpatient care). This was repeated for inpatient care. For outpatient care, the variable for the health facility visited was recoded into Government health facilities, private health facilities, other/outreach point /community health worker, pharmacy/shop and traditional healer. For inpatient care the categories were Government health facility, private health facility and "other".

Categorical data are presented as a frequency and percentage. $P$ values were calculated using a chi-squared test for categorical variables. Weighted and unweighted analyses were carried out using DHS sampling weights to assess the representativeness of the results to the whole population. We used the sample weights provided by the Namibia DHS for individual surveys. Unweighted analyses are presented, with weighted results presented in the Additional file 1.

First, the prevalence and distribution of health insurance coverage by sociodemographic characteristics was explored. In supplementary analyses, we investigated health insurance coverage by different insurance types, which included employer-provided, social security, private and "other" insurance, and how this differed by sex.

We then explored health service utilisation as a function of health insurance coverage and other sociodemographic factors. This involved two separate outcomes: whether an individual sought outpatient care in the four weeks preceding the survey; and whether an individual sought inpatient care in the six months preceding the survey. These questions were asked as part of the Household Questionnaire. The household member was identified by a line number; therefore, their health seeking behaviour can be linked to information collected as part of the Woman's or Man's Questionnaires. We explored the distribution of individuals who sought inpatient and outpatient care, respectively, by health insurance status and sociodemographic characteristics: health insurance, age, sex, education, wealth, residence type, marital status and occupation. The healthcare provider where care was sought was also explored for both inpatient and outpatient care.

Due to the potential for clustering of exposure and outcome variables at the household, EA and regional level, intraclass correlation coefficients (ICCs) were used to assess clustering of outcome and exposure variables at these levels. ICCs were calculated for each exposure and outcome at the household, EA and regional level and are presented with $95 \%$ confidence intervals (95\% CIs).

Univariable and multivariable mixed effects Poisson regression analyses were first carried out to explore the association between health insurance and inpatient and outpatient care-seeking, respectively. For both outcomes (sought outpatient care and sought inpatient care), univariable Poisson regression analyses were first carried out (Model 1) to assess the association between the outcomes and health insurance and other potentially confounding sociodemographic factors of interest (age, sex, education, wealth, residence type, marital status and occupation). In Model 2, region, EA and household were included as mixed effects. Finally, in the fully-adjusted multivariable mixed effects model (Model 3), we adjusted for regional, EA and household clustering, and all sociodemographic factors in addition to the primary exposure of interest: health insurance. In mixed effects models, 95\% CIs were generated using cluster-robust standard errors.

Multivariable mixed effects Poisson regression analyses were also conducted to explore the sociodemographic factors associated with health insurance. In Model 1 we assessed the univariable association between health insurance and each of the exposures of interest: age, sex, education, wealth, occupation, residence type and marital status. In Model 2, region, EA and household were included as mixed effects. Model 3 was a multivariable mixed effects model which adjusted for all exposures listed above and adjusted for clustering at the regional, EA and household level. In mixed effects models, 95\% CIs were generated using cluster-robust standard errors. Effect modification was assessed by stratifying fully-adjusted analyses (Model 3) by sex, education and wealth. We also assessed whether there was statistical evidence of interaction between sex and education, sex and wealth, and education and wealth, in regards to their association with health insurance, using likelihood ratio tests to compare models with and without an interaction term.

\section{Results}

Weighted and unweighted analyses were conducted; here we present unweighted results, with weighted results presented in Additional file 1: Table S1 and Table 
S2. No material difference was observed between weighted and unweighted results.

\section{DHS population}

Due to survey design, in this subset of 14,443 individuals from the 2013 Namibia DHS, 69.1\% were women (Table 1). The population size decreased with increasing age group.
The majority of individuals were educated to secondary level (60.2\%). The largest proportion of the population was in the fourth wealth quintile $(23.4 \%)$ and the smallest in the lowest quintile (15.9\%). There was an equal distribution by residence type, as to be expected from the study design (urban: $50.9 \%$ and rural: $49.1 \%$ ). This is broadly reflective of Namibia's population. Most

Table 1 Distribution of the population by sociodemographic characteristics, stratified by sex

\begin{tabular}{|c|c|c|c|}
\hline Sociodemographic characteristics & All No. (\%) & Men No. (\%) & Women No. (\%) \\
\hline \multicolumn{4}{|l|}{ Sex } \\
\hline Men & 4458 (30.9) & - & - \\
\hline Women & $9985(69.1)$ & - & - \\
\hline \multicolumn{4}{|l|}{ Age group } \\
\hline $15-19$ & $2734(18.9)$ & $880(19.7)$ & $1854(18.6)$ \\
\hline $20-24$ & $2485(17.2)$ & 769 (17.3) & $1716(17.2)$ \\
\hline $25-29$ & $2100(14.5)$ & $609(13.7)$ & $1491(14.9)$ \\
\hline $30-34$ & $1769(12.3)$ & $512(11.5)$ & $1257(12.6)$ \\
\hline $35-39$ & $1589(11.0)$ & $451(10.1)$ & $1138(11.4)$ \\
\hline $40-44$ & $1341(9.3)$ & $400(9.0)$ & $941(9.4)$ \\
\hline $45-49$ & $1056(7.3)$ & $308(6.9)$ & $748(7.5)$ \\
\hline $50-64$ & $1369(9.5)$ & $529(11.9)$ & $840(8.4)$ \\
\hline \multicolumn{4}{|l|}{ Education level } \\
\hline No education & $1213(8.4)$ & $491(11.0)$ & $722(7.2)$ \\
\hline Primary & $3470(24.0)$ & $1172(26.3)$ & $2298(23.0)$ \\
\hline Secondary & $8688(60.2)$ & $2466(55.3)$ & $6222(62.3)$ \\
\hline Higher & $1072(7.4)$ & $329(7.4)$ & $743(7.4)$ \\
\hline \multicolumn{4}{|l|}{ Wealth quintile } \\
\hline Lowest & $2301(15.9)$ & $668(15.0)$ & $1633(16.4)$ \\
\hline Second & $2678(18.5)$ & $861(19.3)$ & $1817(18.2)$ \\
\hline Middle & $3048(21.1)$ & $1003(22.5)$ & $2045(20.5)$ \\
\hline Fourth & 3381 (23.4) & $1036(23.2)$ & $2345(23.5)$ \\
\hline Highest & 3035 (21.0) & $890(20.0)$ & $2145(21.5)$ \\
\hline \multicolumn{4}{|l|}{ Residence type } \\
\hline Urban & $7351(50.9)$ & 2210 (49.6) & $5141(51.5)$ \\
\hline Rural & $7092(49.1)$ & $2248(50.4)$ & $4844(48.5)$ \\
\hline \multicolumn{4}{|l|}{ Marital status } \\
\hline Never married & 7947 (55.0) & $2628(59.0)$ & $5319(53.3)$ \\
\hline Currently married & 3093 (21.4) & $974(21.9)$ & $2119(21.2)$ \\
\hline Living with partner & $2347(16.3)$ & $678(15.2)$ & $1669(16.7)$ \\
\hline Formerly/ever married & $1056(7.3)$ & $178(4.0)$ & $878(8.8)$ \\
\hline \multicolumn{4}{|l|}{ Occupation } \\
\hline Professional & $5092(35.3)$ & $1267(28.4)$ & 3825 (38.3) \\
\hline Agricultural & $644(4.5)$ & $442(9.9)$ & $202(2.0)$ \\
\hline Manual & $1435(9.9)$ & $1063(23.8)$ & $372(3.7)$ \\
\hline Unemployed & $7272(50.4)$ & $1686(37.8)$ & $5586(55.9)$ \\
\hline Total & $14,443(100.0)$ & $4458(100.0)$ & $9985(100.0)$ \\
\hline
\end{tabular}


participants were never married (55.0\%), with $21.4 \%$ currently married and $16.3 \%$ living with their partner. Around 50\% were unemployed, whilst $35.3 \%$ were in professional employment. Similar sociodemographic patterns were observed between men and women (Table 1).

As expected due to survey design, there was evidence for clustering of health insurance, inpatient care, outpatient care and sociodemographic factors at the household, EA and regional level (Additional file 1: Table S3). Health insurance was clustered at the household and EA level, outpatient and inpatient care were clustered at the household level, education was clustered at the household, and EA level, wealth was clustered at the EA and regional level, residence type was clustered at the regional level and marital status and occupation were clustered at the household level.

\section{Health insurance coverage}

Overall we found that $17.5 \%$ of this DHS population had health insurance. A higher proportion of men were insured compared to women $(20.2 \%$ vs $16.2 \%)$ (Table 2). There was a positive relationship between age and health insurance coverage, ranging from $10.0 \%$ in those aged $15-19$ years to $30.8 \%$ in those aged $45-49$ years $(p<0.001)$. In these descriptive analyses, the coverage of health insurance increased with levels of education and wealth $(p<0.001)$. We also found that health insurance coverage was notably higher in urban dwellers at $25.7 \%$ compared to $8.9 \%$ in the rural population $(p<0.001)$. Those who were currently married had the highest coverage of health insurance at $36.8 \%$. As may be expected, health insurance coverage was highest in those in professional employment at $30.8 \%$; however, surprisingly, $7.3 \%$ of the unemployed population were insured. The majority of the insured population had employer-provided insurance (54.5\%); $29.4 \%$ had social security insurance and $21.4 \%$ were covered by private insurance (Additional file 1: Figure S1).

\section{Association between health insurance and health service utilisation}

To better understand the role of health insurance in health service utilisation, we assessed health insurance as a determinant of utilisation of inpatient (six months prior to the survey) and outpatient care (four weeks prior to the survey). A total of 1355 individuals sought outpatient care in the previous four weeks $(9.4 \% ; 7.6 \%$ of men and $10.2 \%$ of women), whilst 625 individuals sought inpatient care (4.3\%; $2.6 \%$ of men and $5.1 \%$ of women)(Table 3$)$. A higher proportion of those with health insurance sought outpatient and inpatient care compared with the uninsured $(p<0.001)$.
Table 2 Distribution of health insurance coverage by sociodemographic characteristics $(n=14,443)$

\begin{tabular}{|c|c|c|c|}
\hline \multirow{2}{*}{$\begin{array}{l}\text { Sociodemographic } \\
\text { characteristics }\end{array}$} & \multicolumn{3}{|c|}{ Health Insurance Coverage No. (\%) } \\
\hline & No & Yes & $p$ \\
\hline \multicolumn{4}{|l|}{ Sex } \\
\hline Men & $3556(79.8)$ & $902(20.2)$ & \multirow[t]{2}{*}{$<0.001$} \\
\hline Women & 8365 (83.8) & $1620(16.2)$ & \\
\hline \multicolumn{4}{|l|}{ Age group } \\
\hline $15-19$ & $2462(90.1)$ & $272(10.0)$ & \multirow[t]{8}{*}{$<0.001$} \\
\hline $20-24$ & $2220(89.3)$ & $265(10.7)$ & \\
\hline $25-29$ & $1810(86.2)$ & $290(13.8)$ & \\
\hline $30-34$ & $1421(80.3)$ & $348(19.7)$ & \\
\hline $35-39$ & $1254(78.9)$ & $335(21.1)$ & \\
\hline $40-44$ & $988(73.7)$ & $353(26.3)$ & \\
\hline $45-49$ & $731(69.2)$ & $325(30.8)$ & \\
\hline $50-64$ & $1035(75.6)$ & $334(24.4)$ & \\
\hline \multicolumn{4}{|l|}{ Education level } \\
\hline No education & $1165(96.0)$ & $48(4.0)$ & \multirow[t]{4}{*}{$<0.001$} \\
\hline Primary & $3257(93.9)$ & $213(6.1)$ & \\
\hline Secondary & $7140(82.2)$ & $1548(17.8)$ & \\
\hline Higher & $359(33.5)$ & $713(66.5)$ & \\
\hline \multicolumn{4}{|l|}{ Wealth quintile } \\
\hline Lowest & 2265 (98.4) & $36(1.6)$ & \multirow[t]{5}{*}{$<0.001$} \\
\hline Second & 2559 (95.6) & $119(4.4)$ & \\
\hline Middle & $2767(90.8)$ & $281(9.2)$ & \\
\hline Fourth & 2749 (81.3) & $632(18.7)$ & \\
\hline Highest & $1581(52.1)$ & $1454(47.9)$ & \\
\hline \multicolumn{4}{|l|}{ Residence type } \\
\hline Urban & $5463(74.3)$ & $1888(25.7)$ & \multirow[t]{2}{*}{$<0.001$} \\
\hline Rural & $6458(91.1)$ & $634(8.9)$ & \\
\hline \multicolumn{4}{|l|}{ Marital status } \\
\hline Never married & $6988(87.9)$ & $959(12.1)$ & \multirow[t]{4}{*}{$<0.001$} \\
\hline Currently married & $1956(63.2)$ & $1137(36.8)$ & \\
\hline Living with partner & $2084(88.8)$ & $263(11.2)$ & \\
\hline Formerly/ever married & $893(84.6)$ & $163(15.4)$ & \\
\hline \multicolumn{4}{|l|}{ Occupation } \\
\hline Professional & $3523(69.2)$ & 1569 (30.8) & \multirow[t]{5}{*}{$<0.001$} \\
\hline Agricultural & $537(83.4)$ & 107 (16.6) & \\
\hline Manual & $1123(78.3)$ & $312(21.7)$ & \\
\hline Unemployed & $6738(92.7)$ & $534(7.3)$ & \\
\hline Total & $11,921(82.5)$ & $2522(17.5)$ & \\
\hline
\end{tabular}

$p$ value corresponds to a chi-squared test

An equal proportion of insured individuals sought healthcare from private and Government providers for inpatient care (both 49.7\%). By contrast, a higher proportion of the uninsured population visited a Government facility for both inpatient and outpatient care, whilst a higher 
Table 3 The distribution of individuals who sought outpatient and inpatient care ${ }^{a}$ by sociodemographic characteristics $(n=14,443)$

\begin{tabular}{|c|c|c|c|c|c|c|}
\hline \multirow{2}{*}{$\begin{array}{l}\text { Sociodemographic } \\
\text { characteristics }\end{array}$} & \multicolumn{3}{|c|}{ Sought Outpatient care No. (\%) } & \multicolumn{3}{|c|}{ Sought Inpatient care No. (\%) } \\
\hline & No & Yes & $p$ & No & Yes & $p$ \\
\hline \multicolumn{7}{|l|}{ Health insurance } \\
\hline No & $10,916(91.6)$ & $1005(8.4)$ & $<0.001$ & $11,440(96.0)$ & $481(4.0)$ & $<0.001$ \\
\hline Yes & $2172(86.1)$ & $350(13.9)$ & & $2378(94.3)$ & $144(5.7)$ & \\
\hline \multicolumn{7}{|l|}{ Sex } \\
\hline Men & $4119(92.4)$ & $339(7.6)$ & $<0.001$ & $4343(97.4)$ & $115(2.6)$ & $<0.001$ \\
\hline Women & $8969(89.8)$ & $1016(10.2)$ & & $9475(94.9)$ & $510(5.1)$ & \\
\hline \multicolumn{7}{|l|}{ Age group } \\
\hline $15-19$ & $2616(95.7)$ & $118(4.3)$ & $<0.001$ & $2670(97.7)$ & $64(2.3)$ & $<0.001$ \\
\hline $20-24$ & $2338(94.1)$ & $147(5.9)$ & & $2393(96.3)$ & $92(3.7)$ & \\
\hline $25-29$ & $1913(91.1)$ & $187(8.9)$ & & $1985(94.5)$ & $115(5.5)$ & \\
\hline $30-34$ & $1579(89.3)$ & $190(10.7)$ & & $1665(94.1)$ & $104(5.9)$ & \\
\hline $35-39$ & $1424(89.6)$ & $165(10.4)$ & & $1510(95.0)$ & $79(5.0)$ & \\
\hline $40-44$ & $1178(87.8)$ & $163(12.2)$ & & $1277(95.2)$ & $64(4.8)$ & \\
\hline $45-49$ & $898(85.0)$ & $158(15.0)$ & & $1011(95.7)$ & $45(4.3)$ & \\
\hline $50-64$ & $1142(83.4)$ & 227 (16.6) & & 1307 (95.5) & $62(4.5)$ & \\
\hline \multicolumn{7}{|l|}{ Education level } \\
\hline No education & 1111 (91.6) & $102(8.4)$ & $<0.001$ & 1180 (97.3) & $33(2.7)$ & 0.014 \\
\hline Primary & $3133(90.3)$ & $337(9.7)$ & & $3323(95.8)$ & $147(4.2)$ & \\
\hline Secondary & 7916 (91.1) & $772(8.9)$ & & $8300(95.5)$ & $388(4.5)$ & \\
\hline Higher & $928(86.6)$ & $144(13.4)$ & & $1015(94.7)$ & $57(5.3)$ & \\
\hline \multicolumn{7}{|l|}{ Wealth quintile } \\
\hline Lowest & $2086(90.7)$ & $215(9.3)$ & $<0.001$ & 2207 (95.9) & $94(4.1)$ & 0.878 \\
\hline Second & 2446 (91.3) & $232(8.7)$ & & $2557(95.5)$ & $121(4.5)$ & \\
\hline Middle & $2795(91.7)$ & $253(8.3)$ & & $2919(95.8)$ & $129(4.2)$ & \\
\hline Fourth & $3074(90.9)$ & $307(9.1)$ & & $3227(95.5)$ & $154(4.6)$ & \\
\hline Highest & $2687(88.5)$ & $348(11.5)$ & & 2908 (95.8) & $127(4.2)$ & \\
\hline \multicolumn{7}{|l|}{ Residence type } \\
\hline Urban & $6643(90.4)$ & 708 (9.6) & 0.295 & $7012(95.4)$ & $339(4.6)$ & 0.087 \\
\hline Rural & $6445(90.9)$ & $647(9.1)$ & & $6806(96.0)$ & $286(4.0)$ & \\
\hline \multicolumn{7}{|l|}{ Marital status } \\
\hline Never married & 7406 (93.2) & $541(6.8)$ & $<0.001$ & $7672(96.5)$ & $275(3.5)$ & $<0.001$ \\
\hline Currently married & $2681(86.7)$ & $412(13.3)$ & & $2931(94.8)$ & $162(5.2)$ & \\
\hline Living with partner & $2129(90.7)$ & $218(9.3)$ & & $2211(94.2)$ & $136(5.8)$ & \\
\hline Formerly/ever married & $872(82.6)$ & $184(17.4)$ & & $1004(95.1)$ & $52(4.9)$ & \\
\hline \multicolumn{7}{|l|}{ Occupation } \\
\hline Professional & $4500(88.4)$ & $592(11.6)$ & $<0.001$ & $4841(95.1)$ & $251(4.9)$ & 0.047 \\
\hline Agricultural & $580(90.1)$ & $64(9.9)$ & & 622 (96.6) & $22(3.4)$ & \\
\hline Manual & 1313 (91.5) & $122(8.5)$ & & 1382 (96.3) & $53(3.7)$ & \\
\hline Unemployed & $6695(92.1)$ & $577(7.9)$ & & $6973(95.9)$ & $299(4.1)$ & \\
\hline Total & 13,088 (90.6) & 1355 (9.4) & & $13,818(95.7)$ & $625(4.3)$ & \\
\hline
\end{tabular}

$p$ value corresponds to a chi-squared test

${ }^{a}$ Outpatient care sought in four weeks prior to survey and inpatient care sought in six months prior to survey 
proportion of the insured population visited a private facility for outpatient care $(50.0 \%$ private; $22.3 \%$ Government) (Additional file 1: Figures. S2A and B). We also found that a higher proportion of women sought outpatient care than men $(10.2 \%$ vs $7.6 \%, p<0.001)$ and that the prevalence of seeking outpatient care increased with age $(p<0.001)$, education level $(p<0.001)$ and wealth $(p<0.001)$ (Table 3$)$. A higher proportion of the insured population sought inpatient care compared with the uninsured $(5.7 \%$ vs $4.0 \%, p<0.001)$. The prevalence of inpatient care increased with education level $(p=0.014)$. We did not observe a significant difference in inpatient care by wealth or residence type $(p>0.05)$.

To explore the association between health insurance and both outpatient and inpatient care, multivariable mixed effects analyses were conducted to account for clustering and covariates. We found that health insurance was significantly associated with seeking outpatient (Model 3 RR: 1.28; 95\% CI: 1.08-1.52; $p=0.005$ ) and inpatient care (Model 3 RR: 1.52; 95\% CI: 1.261.82; $p<0.001$ )(Fig. 1 and Additional file 1: Table S4 and Table S5). This suggests a role for health insurance in health service utilisation. Importantly, women were more likely to seek inpatient and outpatient care, irrespective of insurance status and other sociodemographic factors (Additional file 1: Table S4 and Table S5).

\section{Sociodemographic determinants of health insurance}

As we found an association between health insurance and health service utilisation, we aimed to explore the sociodemographic factors associated with being insured. In multivariable mixed effects Poisson regression analyses (Model 3 ), women were significantly less likely to be insured than

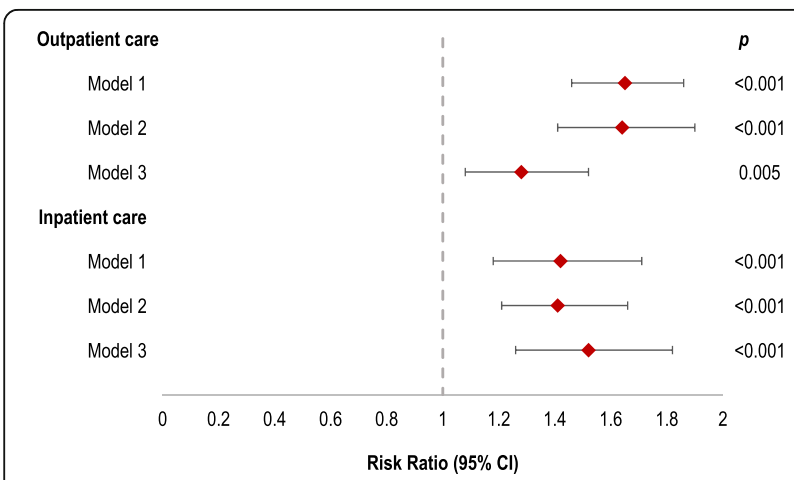

Fig. 1 The association between health insurance and inpatient and outpatient care $(n=14,443)$. Model 1: univariable association between health insurance and inpatient and outpatient care, respectively | Model 2: univariable mixed effects model accounting for regional, enumeration area (EA) and household clustering | Model 3: multivariable mixed effects model, accounting for regional, EA and household clustering and adjusting for age, education, wealth, residence type, marital status and occupation | 95\% Cl: 95\% Confidence Interval men (RR: 0.83; 95\% CI: 0.74-0.94; $p=0.003$ ), irrespective of age, education, wealth, residence type, marital status and occupation and clustering (Table 4). Education and wealth were both independently positively associated with health insurance.

To further explore the role of sociodemographic factors in health insurance coverage and assess effect modification, we conducted multivariable mixed effects analyses, stratified by sex, education and wealth. When we stratified by sex, we found that education was more strongly associated with health insurance in women than in men (Additional file 1: Table S6). Further, we found that as education level increased, women were more likely to be insured (Fig. 2 and Additional file 1: Table S7). We identified a significant interaction between sex and education ( $p$ for interaction <0.001) (Fig. 2 and Additional file 1: Table S7). We also found that wealth modified the association between education and health insurance, with education being more strongly associated with insurance in lower wealth quintiles ( $p$ for interaction $=0.002$ )(Fig. 3 and Additional file 1: Table S8). Therefore, education is likely to play a particularly important role in health insurance coverage in less wealthy households. Due to convergence issues, we were unable to stratify by the lowest wealth quintile.

\section{Discussion}

Our findings suggest that health insurance plays a role in healthcare access and health service utilisation in Namibia; however, just $17.5 \%$ of this DHS population were insured, leaving a large proportion of the population potentially disadvantaged when accessing healthcare. We found that sex, education and wealth were independently associated with health insurance. Education also modified the association between health insurance and sex and wealth, whereby education was more strongly associated with health insurance in the less wealthy and women. Furthermore, the likelihood of women being insured increased with education level.

There are many factors that may contribute to health insurance coverage; our findings that wealth and education are associated with having health insurance are consistent with those from other settings [32-38]. Wealthier households often have more disposable income to afford insurance. In Namibia, a country with a high income inequality, poorer households can only allocate minor shares of expenditure to healthcare [8]. Furthermore, the structure of many health insurance schemes favours wealthier populations; for example, high annual premiums instead of installment payment options and reimbursement mechanisms, which mean healthcare must first be paid for OOP [42]. The association between sex and health insurance is more complex; by contrast to our findings, studies in Ghana and 
Table 4 Association between sociodemographic factors and health insurance $(n=14,443)$

\begin{tabular}{|c|c|c|c|c|c|c|}
\hline \multirow{2}{*}{$\begin{array}{l}\text { Sociodemographic } \\
\text { characteristics }\end{array}$} & \multicolumn{2}{|l|}{ Model 1} & \multicolumn{2}{|l|}{ Model 2} & \multicolumn{2}{|l|}{ Model 3} \\
\hline & RR $(95 \% \mathrm{Cl})$ & $p$ & RR $(95 \% \mathrm{Cl})$ & $p$ & RR $(95 \% \mathrm{Cl})$ & $p$ \\
\hline \multicolumn{7}{|l|}{ Sex } \\
\hline Men & 1.00 (reference) & & 1.00 (reference) & & 1.00 (reference) & \\
\hline Women & $0.80(0.74-0.87)$ & $<0.001$ & $0.79(0.71-0.88)$ & $<0.001$ & $0.83(0.74-0.94)$ & 0.003 \\
\hline \multicolumn{7}{|l|}{ Age group } \\
\hline $15-19$ & 1.00 (reference) & & 1.00 (reference) & & 1.00 (reference) & \\
\hline $20-24$ & $1.07(0.91-1.27)$ & 0.421 & $0.99(0.80-1.23)$ & 0.951 & $0.64(0.54-0.75)$ & $<0.001$ \\
\hline $25-29$ & $1.39(1.18-1.64)$ & $<0.001$ & $1.30(1.00-1.68)$ & 0.049 & $0.70(0.60-0.82)$ & $<0.001$ \\
\hline $30-34$ & $1.98(1.69-2.32)$ & $<0.001$ & $1.80(1.40-2.32)$ & $<0.001$ & $0.83(0.73-0.96)$ & 0.010 \\
\hline $35-39$ & $2.12(1.81-2.49)$ & $<0.001$ & $1.97(1.45-2.68)$ & $<0.001$ & $0.89(0.75-1.06)$ & 0.200 \\
\hline $40-44$ & $2.65(2.26-3.10)$ & $<0.001$ & $2.28(1.67-3.10)$ & $<0.001$ & $0.98(0.82-1.16)$ & 0.784 \\
\hline $45-49$ & $3.09(2.63-3.63)$ & $<0.001$ & $2.66(1.98-3.57)$ & $<0.001$ & $1.13(0.93-1.38)$ & 0.233 \\
\hline $50-64$ & $2.45(2.09-2.88)$ & $<0.001$ & $2.35(1.80-3.07)$ & $<0.001$ & $1.08(0.87-1.33)$ & 0.503 \\
\hline \multicolumn{7}{|l|}{ Education level } \\
\hline No education & 1.00 (reference) & & 1.00 (reference) & & 1.00 (reference) & \\
\hline Primary & $1.55(1.13-2.12)$ & 0.006 & $1.53(1.13-2.07)$ & 0.006 & $1.28(0.99-1.66)$ & 0.060 \\
\hline Secondary & $4.50(3.38-6.00)$ & $<0.001$ & $3.44(2.73-4.34)$ & $<0.001$ & 2.35 (1.92-2.88) & $<0.001$ \\
\hline Higher & $16.81(12.55-22.51)$ & $<0.001$ & $9.42(6.14-14.47)$ & $<0.001$ & $3.98(3.11-5.10)$ & $<0.001$ \\
\hline \multicolumn{7}{|l|}{ Wealth quintile } \\
\hline Lowest & 1.00 (reference) & & 1.00 (reference) & & 1.00 (reference) & \\
\hline Second & $2.84(1.96-4.12)$ & $<0.001$ & $2.89(1.76-4.75)$ & $<0.001$ & $2.52(1.54-4.13)$ & $<0.001$ \\
\hline Middle & $5.89(4.17-8.34)$ & $<0.001$ & $6.03(4.07-8.95)$ & $<0.001$ & $4.44(2.90-6.82)$ & $<0.001$ \\
\hline Fourth & $11.95(8.54-16.72)$ & $<0.001$ & $12.86(8.97-18.43)$ & $<0.001$ & $7.58(5.05-11.39)$ & $<0.001$ \\
\hline Highest & $30.62(22.00-42.62)$ & $<0.001$ & $30.86(21.84-43.60)$ & $<0.001$ & $13.47(9.06-20.04)$ & $<0.001$ \\
\hline \multicolumn{7}{|l|}{ Residence type } \\
\hline Urban & 1.00 (reference) & & 1.00 (reference) & & 1.00 (reference) & \\
\hline Rural & $0.35(0.32-0.38)$ & $<0.001$ & $0.42(0.35-0.50)$ & $<0.001$ & $1.03(0.90-1.17)$ & 0.676 \\
\hline \multicolumn{7}{|l|}{ Marital status } \\
\hline Never married & 1.00 (reference) & & 1.00 (reference) & & 1.00 (reference) & \\
\hline Currently married & $3.05(2.80-3.32)$ & $<0.001$ & $2.67(2.20-3.24)$ & $<0.001$ & $1.68(1.46-1.93)$ & $<0.001$ \\
\hline Living with partner & $0.93(0.81-1.06)$ & 0.287 & $1.06(0.89-1.27)$ & 0.522 & $1.06(0.94-1.19)$ & 0.354 \\
\hline Formerly/ever married & $1.28(1.08-1.51)$ & 0.004 & $1.40(1.24-1.58)$ & $<0.001$ & $1.13(1.04-1.24)$ & 0.005 \\
\hline \multicolumn{7}{|l|}{ Occupation } \\
\hline Professional & 1.00 (reference) & & 1.00 (reference) & & 1.00 (reference) & \\
\hline Agricultural & $0.54(0.44-0.66)$ & $<0.001$ & $0.79(0.69-0.91)$ & 0.001 & $0.89(0.76-1.05)$ & 0.168 \\
\hline Manual & $0.71(0.63-0.80)$ & $<0.001$ & $0.79(0.70-0.90)$ & $<0.001$ & $0.86(0.78-0.95)$ & 0.003 \\
\hline Unemployed & $0.24(0.22-0.26)$ & $<0.001$ & $0.32(0.23-0.44)$ & $<0.001$ & $0.44(0.35-0.55)$ & $<0.001$ \\
\hline
\end{tabular}

RR: Risk ratio obtained from Poisson regression analyses | 95\% Cl: $95 \%$ Confidence Intervals

Model 1: univariable association between exposure and having health insurance

Model 2: same as model one with region, enumeration area (EA) and household included as random effects (mixed effects Poisson regression)

Model 3: additionally adjusted for all covariates included in the table (multivariable mixed effects Poisson regression)

South Africa identified men to be less likely to have health insurance than women [32, 34]. It has also been suggested that women, as care-givers, are more conscious of the importance of healthcare and insurance and may be more likely to seek healthcare [34, 43]. Similarly, in our analysis, women were more likely to have sought healthcare than men but this health-seeking attitude was not reflected in the patterns of health insurance coverage.

Education, as well as being an independent determinant of health insurance in this Namibian population, also 


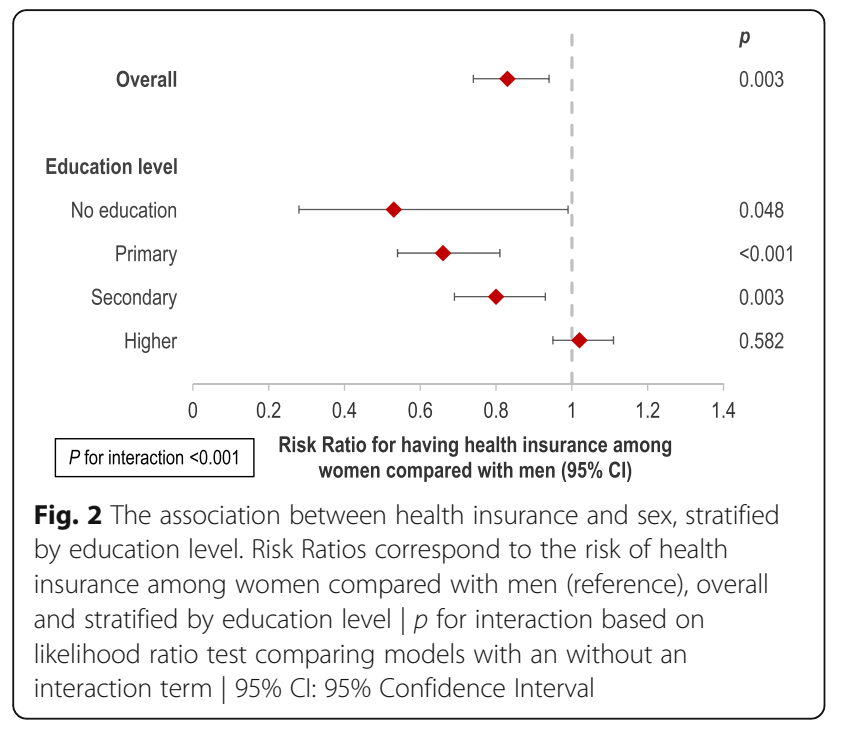

modified sex and wealth disparities in insurance coverage. We found that greater educational attainment increased the likelihood of women being insured. Additionally, when women were educated to higher level there was no difference in insurance compared with men, irrespective of wealth and other sociodemographic factors. This indicates that progression through the education system is especially important for women being insured and is consistent with previous findings that secondary or higher educational attainment is linked to increased coverage of health insurance in other sub-Saharan African populations $[35,36]$. We also found that education level was more strongly associated with health insurance in less wealthy populations. Our findings therefore highlight the value and impact of education on health insurance. Education may influence health insurance coverage in a number of

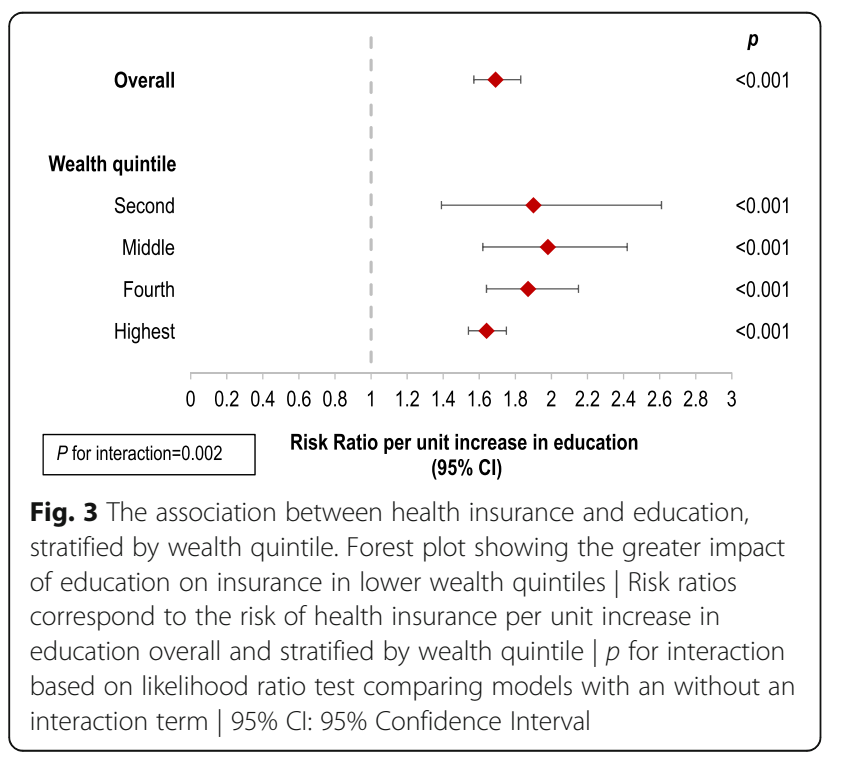

ways. Education could improve knowledge and attitudes towards health seeking and the value of health insurance. In Namibia, education has been associated with willingness to join and pay for low-cost health insurance [44] and has also been associated with increased awareness about insurance schemes elsewhere [45, 46]. Therefore, education may empower women and relatively poorer individuals to make choices, including decisions around health [47].

Due to the cross-sectional nature of the data, it was not possible to assess the temporality of the associations observed between sociodemographic factors and health insurance nor between health insurance and health service utilisation. Wealth was also measured at the household level, restricting our understanding of the effects of individual wealth on health insurance. Other factors beyond the scope of this analysis may also influence health service utilisation or health insurance coverage, such as the likelihood that the consumer will become ill, preexisting medical conditions, or individual knowledge, attitudes and practice towards health and insurance $[42,48-50]$. It was also not possible to explore the willingness to pay for health insurance. A further limitation is that the data used for these analyses were collected in 2013, and thus may not fully reflect the situation in Namibia at present.

Education and public engagement have been identified as key strategies for the uptake and acceptability of health insurance in other settings $[49,51]$. Improving access to, and the quality of, education is an important component of multiple government strategies in Namibia $[29,52,53]$ and our findings further highlight the importance of the country's commitments to improving education. Although access to education in Namibia is high overall, including for women, attendance and the quality of education is variable and often inadequate in lower-income communities, marginalised populations and in remote or rural areas [29]. Whilst a high percentage of the Namibian population complete primary education, transition to and completion of secondary and higher education could be improved [29]. Our findings suggest that improvements in access to education may help individuals to better manage their health but further research is needed to better understand this relationship. These findings have implications for the design and implementation of strategies to scale-up health insurance coverage or improve financial protection for more vulnerable populations. Health insurance could be scaled-up through community engagement strategies that utilise the media and other advocacy tools [54, 55]. Furthermore, mechanisms to make health insurance more affordable through subsidisation, for example, may help to increase uptake [12, 44]. Employer-provided schemes, which accounted for more than half of insurance in this population, could be expanded to the informal sector. For 
example, one study in Namibia found that employers on commercial farms were receptive to providing a co-pay insurance plan for their employees [56]. An alternative solution in countries like Namibia, where around a fifth of healthcare is financed via private health insurance, is that Governments could target public financing to populations less able or likely to participate in voluntary insurance schemes [57].

\section{Conclusions}

In conclusion, health insurance is an important component of health service utilisation in Namibia, but inequities in the coverage of these insurance schemes means that many individuals could be at a disadvantage when accessing healthcare. Specifically, women and those with lower levels of education and wealth were less likely to be covered by health insurance. Our findings suggest that, in Namibia, education may be important for bridging gaps in health insurance coverage for women and the less wealthy, but further research is needed to fully understand this relationship. These findings could inform the design and implementation of interventions to scale-up health insurance or provide greater financial protection from healthcare-associated costs for uninsured populations. Additional research is also needed to evaluate the effectiveness of insurance schemes and the quality of care received as a result of being insured in Namibia and elsewhere if UHC is to be realised.

\section{Additional file}

Additional file 1: Figure S1. Proportion of insured individuals with each type of health insurance, stratified by sex. Number labels correspond to the number of individuals. Figure S2. Type of healthcare provider where inpatient and outpatient care was sought by health insurance coverage $\mid \mathrm{A}$ insured $n=350$ uninsured $n=1005$; $B$ insured $n=143$ uninsured $n=479 \mid$ HF: health facility | OP: outreach point | CHW: community health worker. Table S1. Weighted prevalence of health insurance by sociodemographic factors. Table S2. Weighted prevalence of seeking outpatient and inpatient care* by sociodemographic characteristics. Table S3. Clustering of sociodemographic factors within households, EAs and regions $(n=14,443)$. Table S4. Association between exposures of interest and seeking outpatient care in the four weeks prior to the survey $(n=14,443)$. Table S5. Association between exposures of interest and inpatient care $(n=14,443)$. Table S6. Association between sociodemographic factors and health insurance, stratified by sex. Table S7. Association between sociodemographic factors and health insurance, stratified by education level. Table S8. Association between sociodemographic factors and health insurance, stratified by wealth quintile. (DOCX $178 \mathrm{~kb})$

\section{Abbreviations}

DHS: Demographic and Health Survey; EA: enumeration area; GDP: Gross Domestic Product; OOP: out-of-pocket; SD: standard deviation; SSA: subSaharan Africa; THE: Total Health Expenditure; UHC: Universal Health Coverage; WHO: World Health Organization

\section{Funding}

The study was supported by the Wellcome Trust (grant number 206194), the African Partnership for Chronic Disease Research (Medical Research Council UK partnership grant number MR/K013491/1), and the National Institute for Health Research Cambridge Biomedical Research Centre (UK).

\section{Availability of data and materials}

The datasets analysed during the current study are available from the DHS Program: https://dhsprogram.com/data/available-datasets.cfm.

\section{Authors' contributions}

SA analysed and interpreted DHS data and was a primary contributor in writing the manuscript. EY and MS supervised and guided analytical work and the writing of this manuscript. All authors read and approved the final manuscript.

\section{Ethics approval and consent to participate}

Ethical review and approval for procedures and questionnaires for standard DHS surveys is provided by ICF Institutional Review Board (IRB). Countryspecific DHS survey protocols are reviewed by the ICF IRB and typically by an IRB in the host country. Verbal consent is obtained from the participant and a signature is provided by the interviewer to acknowledge that this event has taken place.

\section{Consent for publication}

Not applicable.

Competing interests

The authors declare that they have no competing interests.

\section{Publisher's Note}

Springer Nature remains neutral with regard to jurisdictional claims in published maps and institutional affiliations.

Received: 15 June 2018 Accepted: 6 January 2019

Published online: 22 January 2019

References

1. World Health Organization. What is universal health coverage? 2014. Available from: http://www.who.int/features/qa/universal_health_coverage/ en/. Accessed 12 Mar 2018.

2. World Health Organization and the International Bank for Reconstruction and Development/The World Bank, Tracking Universal Health Coverage: 2017 Global Monitoring Report. 2017: Switzerland.

3. World Bank. Namibia. 2017. Available from: http://data.worldbank.org/ country/namibia. Accessed 14 Aug 2017.

4. Republic of Namibia Ministry of Health and Social Services. Namibia 2014/15 Health Accounts Report. Windhoek: Ministry of Health and Social Services; 2017.

5. Republic of Namibia Ministry of Health and Social Services, National Health Policy Framework 2010-2020. 2010, Ministry of Health and Social Services: Windhoek, Namibia.

6. $\mathrm{Xu} \mathrm{K}$, et al. Exploring the thresholds of health expenditure for protection against nancial risk, in Health systems financing: the path to universal coverage. Geneva: World Health Organization; 2010.

7. The World Bank. GINI index (World Bank estimate). World Development Indicators. Available from: http://databank.worldbank.org/data/reports. aspx? source=2\&series=SI.POV.GINI. Accessed 16 Mar 2018.

8. Central Bureau of Statistics National Planning Commission, A Review of Poverty and Inequality in Namibia 2008, Central Bureau of Statistics National Planning Commission: Windoek, Namibia.

9. Dieleman $J$, et al. Trends in future health financing and coverage: future health spending and universal health coverage in 188 countries. Lancet. 2016;391:1783-98.

10. World Health Organization Regional Office for Africa, A.H.O. Namibia: Universal coverage. Available from: http://www.aho.afro.who.int/profiles information/index.php/Namibia:Universal_coverage. Accessed 4 Apr 2018.

11. Reeves $A$, et al. Financing universal health coverage--effects of alternative tax structures on public health systems: cross-national modelling in 89 lowincome and middle-income countries. Lancet. 386(9990):274-80. 
12. World Bank; World Health Organization; JICA; The Global Fund to Fight AIDS, Tuberculosis and Malaria; and the African Development Bank. 2016. UHC in Africa: A Framework for Action. Washington, DC: World Bank. License: Creative Commons Attribution CC BY 3.0 IGO

13. Abera Abaerei A, Ncayiyana J, Levin J. Health-care utilization and associated factors in Gauteng province, South Africa. Glob Health Action. 2017;10(1): 1305765.

14. Wang W, Temsah G, Mallick L. The impact of health insurance on maternal health care utilization: evidence from Ghana, Indonesia and Rwanda. Health Policy Plan. 2017;32(3):366-75.

15. Dalinjong PA, et al. The association between health insurance status and utilization of health services in rural northern Ghana: evidence from the introduction of the National Health Insurance Scheme. J Health Popul Nutr. 2017;36(1):42.

16. Chomi EN, et al. Health care seeking behaviour and utilisation in a multiple health insurance system: does insurance affiliation matter? Int J Equity Health. 2014;13:25

17. Goudge J, et al. Social health insurance contributes to universal coverage in South Africa, but generates inequities: survey among members of a government employee insurance scheme. Int J Equity Health. 2018;17(1):1.

18. McIntyre D, G.B., Mtei G, Meheus F, Thiede M, Akazili J, Ally M, Aikins M, Mulligan JA, Goudge J:, Beyond fragmentation and towards universal coverage: insights from Ghana, South Africa and the United Republic of Tanzania. Bull World Health Organ, 2008. 86.

19. Habib SS, Perveen S, Khuwaja HMA. The role of micro health insurance in providing financial risk protection in developing countries- a systematic review. BMC Public Health. 2016;16:281.

20. Odeyemi IAO, Nixon J. Assessing equity in health care through the national health insurance schemes of Nigeria and Ghana: a review-based comparative analysis. Int J Equity Health. 2013;12:9-9.

21. Nguyen HT, Rajkotia $Y$, Wang $H$. The financial protection effect of Ghana National Health Insurance Scheme: evidence from a study in two rural districts. Int J Equity Health. 2011;10:4

22. Aryeetey GC, et al. Can health insurance protect against out-of-pocket and catastrophic expenditures and also support poverty reduction? Evidence from Ghana's National Health Insurance Scheme. Int J Equity Health. 2016; 15(1):116.

23. Kangmennaang J, Mkandawire $\mathrm{P}$, Luginaah I. What prevents men aged 40 64 years from prostate Cancer screening in Namibia? J Cancer Epidemiol. 2016;2016:7962502.

24. Kangmennaang J, Mkandawire P, Luginaah I. Breast cancer screening among women in Namibia: explaining the effect of health insurance coverage and access to information on screening behaviours. Glob Health Promot. 2017;1:1757975917727017.

25. Kangmennaang J, et al. Investigating the disparities in cervical cancer screening among Namibian women. Gynecol Oncol. 2015;138(2):411-6.

26. Zere $\mathrm{E}$, et al. Inequities in skilled attendance at birth in Namibia: a decomposition analysis. BMC Pregnancy Childbirth. 2011;11:34.

27. Thogarapalli $\mathrm{N}$, et al. Gestational age at first antenatal visit in Namibia. Int Public Health. 2016;61(9):1089-97.

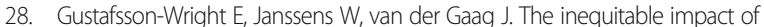
health shocks on the uninsured in Namibia. Health Policy Plan. 2011;26(2):142-56.

29. National Planning Commission, Namibia's 5th National Development Plan (NDP5). 2017, National Planning Commission: Windhoek, Namibia.

30. Namibia Central Bureau of Statistics Naitonal Planning Commission. A review of poverty and inequality in Namibia. Namibia: Central Bureau of Statistics Naitonal Planning Commission; 2008

31. Namibia Statistics Agency, The Namibia Labour Force Survey 2016 Report. 2016, Namibia Statistics Agency: Windhoek, Namibia

32. Govender $V$, et al. Moving towards universal coverage in South Africa? Lessons from a voluntary government insurance scheme. Glob Health Action. 2013;6:19253.

33. Dong $\mathrm{H}$, et al. Willingness-to-pay for community-based insurance in Burkina Faso. Health Econ. 2003;12(10):849-62.

34. Boateng D, Awunyor-Vitor D. Health insurance in Ghana: evaluation of policy holders' perceptions and factors influencing policy renewal in the Volta region. Int J Equity Health. 2013;12:50.

35. Kirigia JM, et al. Determinants of health insurance ownership among south African women. BMC Health Serv Res. 2005;5(1):17.
36. Kimani JK, et al. Determinants of health insurance ownership among women in Kenya: evidence from the 2008-09 Kenya demographic and health survey. Int J Equity Health. 2014;13:27.

37. Kusi A, et al. Refusal to enrol in Ghana's National Health Insurance Scheme: is affordability the problem? Int J Equity Health. 2015;14:2.

38. Kotoh AM, Van der Geest S. Why are the poor less covered in Ghana's national health insurance? A critical analysis of policy and practice. Int J Equity Health. 2016;15:34.

39. The Nambia Ministry of Health and Social Services (MoHSS) and ICF International. 2014. The Namibia Demographic and Health Survey 2013. Windhoek, Namibia, and Rockville, Maryland, USA: MoHSS and ICF International.

40. MEASURE DHS and ICF International, Standard recode manual for DHS 6, in Demographic and Health Surveys Methodology 2013, USAID. https://www. dhsprogram.com/pubs/pdf/DHSG4/Recode6_DHS_22March2013_DHSG4.pdf.

41. Demographic and Health Survey Program. Wealth Index Construction. Available from: http://www.dhsprogram.com/topics/wealth-index/WealthIndex-Construction.cfm. Accessed 7 July 2016.

42. Umeh CA, Feeley FG. Inequitable access to health care by the poor in community-based health insurance programs: a review of studies from lowand middle-income countries. Glob Health Sci Pract. 2017;5(2):299-314.

43. van der Wielen N, Channon AA, Falkingham J. Does insurance enrolment increase healthcare utilisation among rural-dwelling older adults? Evidence from the National Health Insurance Scheme in Ghana. BMJ Global Health. 2018;3(1).

44. Gustafsson-Wright E, Asfaw A, van der Gaag J. Willingness to pay for health insurance: an analysis of the potential market for new low-cost health insurance products in Namibia. Soc Sci Med. 2009;69(9):1351-9.

45. Adewole DA, et al. Expanding health insurance scheme in the informal sector in Nigeria: awareness as a potential demand-side tool. Pan Afr Med J. 2017;27:52.

46. Noubiap JJ, et al. Community-based health insurance knowledge, concern, preferences, and financial planning for health care among informal sector workers in a health district of Douala, Cameroon. Pan Afr Med J. 2013;16:17.

47. Klugman J, Hanmer L, Twigg S, Hasan T, McCleary-Sills J, Santamaria J. Voice and Agency: Empowering Women and Girls for Shared Prosperity. Washington, DC: World Bank Group; 2014. @ World Bank. https:// openknowledge.worldbank.org/handle/10986/19036. License: CC BY 3.0 IGO

48. Steyn $\mathrm{K}$, et al. Determinants and treatment of hypertension in south Africans: the first demographic and health survey. S Afr Med J. 2008;98(5): 376-80.

49. Mulupi S, Kirigia D, Chuma J. Community perceptions of health insurance and their preferred design features: implications for the design of universal health coverage reforms in Kenya. BMC Health Serv Res. 2013;13:474

50. Obse A, Hailemariam D, Normand C. Knowledge of and preferences for health insurance among formal sector employees in Addis Ababa: a qualitative study. BMC Health Serv Res. 2015;15:318.

51. Setswe $\mathrm{G}$, et al. Public awareness and knowledge of the National Health Insurance in South Africa. Pan Afr Med J. 2015;22:19.

52. Republic of Namibia Central Bureau of Statistics and National Planning Commission, A Review of Poverty and Inequality in Namibia. Windhoek: Namibia Central Bureau of Statistics Naitonal Planning Commission; 2008.

53. Republic of Namibia Ministry of Education. In: Republic of Namibia Ministry of Education, editor. Strategic Plan 2012-2017. Namibia; 2012

54. Fadlallah $\mathrm{R}$, et al. Barriers and facilitators to implementation, uptake and sustainability of community-based health insurance schemes in low- and middle-income countries: a systematic review. Int J Equity Health. 2018; $17(1): 13$.

55. Kansanga MM, et al. Examining the association between exposure to mass media and health insurance enrolment in Ghana. Int J Health Plann Manag. 2018.

56. De Beer l, et al. Health care options for commercial farm workers in Namibia. Rural Remote Health. 2011;11(1).

57. Sekhri N, Savedoff W. Private health insurance: implications for developing countries. Bull World Health Organ. 2005;83(2):127-34. 